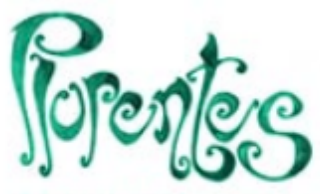

Artes y Letras
Plurentes. Artes y Letras

ISSN: 1853-6212

plurentesunlp@gmail.com

Universidad Nacional de La Plata

Secretaría de Asuntos Académicos

Prosecretaría de Asuntos Académicos

Bachillerato de Bellas Artes, "Prof. Francisco A. De Santo" Argentina

\title{
Poemas
}

\section{Cingolani, Catalina}

\section{Poemas}

Plurentes. Artes y Letras, núm. 11, e016, 2020

Universidad Nacional de La Plata

Secretaría de Asuntos Académicos

Prosecretaría de Asuntos Académicos

Bachillerato de Bellas Artes, "Prof. Francisco A. De Santo"

Argentina

DOI: https://doi.org/10.24215/18536212e016

Atribución no comercial compartir igual (CC BY-NC-SA) 4.0 


\section{Poemas}

\section{Catalina Cingolani}

DOI: https://doi.org/10.24215/18536212e016

Bachillerato de Bellas Artes, Universidad Nacional de La Plata, Argentina

catalinacingolani@hotmail.com

Recepción: 10 Septiembre 2020

Aprobación: 11 Septiembre 2020

Publicación: 26 Octubre 2020

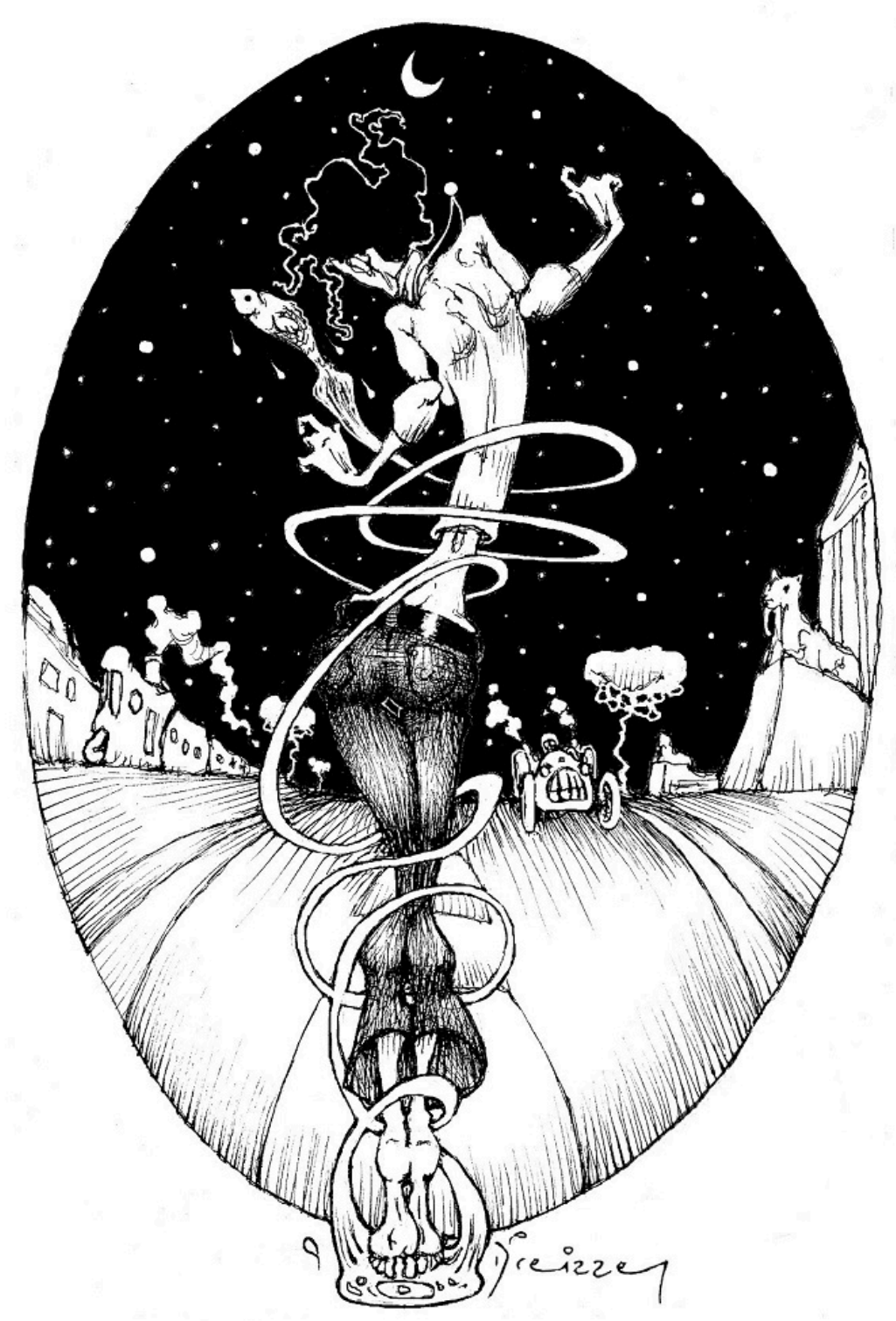

Ilustración: Alberto Dreizzen 
aquí hay un pez

percute
se traba
es un continente una aldea que danza un
verano un cuaderno de dos o tres noches

el pez se agranda se agita entre el ir y venir del agua que lo respira

lo retuerce

lo enrosca

como una constelación que late sobre las márgenes de sus orillas táctiles pero invisibles

aquí hay un pez

víbora almeja

incertidumbre

como las estrellas que tuvimos en ese cielo negro de

Yacanto

tengo que prepararme para nacer de nuevo al pez

sola

en la frgilidad de mis párpados

anoche hablamos sobre el agua

para vos tenía petróleo

para mí no tenía peso 
sin embargo

la tomamos anoche los

dos mientras hablábamos

como cuando vuela la basura cuando se quema

III

estás echado

$$
\text { te morí }
$$

rueda rota de bicicleta
de repente sobrevolar la casa y las formas y saber qué olor tiene la ausencia lo inhóspito también ese silencio rumiante al caminar las paredes verdes y después muy blancas matar las arañas y las teorías los domingos mi paciencia de humedad

todas las explicaciones

te duelo

\section{BY-NC-SA}

